\title{
Review \\ Developments in the clinical understanding of osteoarthritis
} David T Felson

Boston University School of Medicine, Suite 200, 650 Albany Street, Boston, MA 02118, USA

Corresponding author: David T Felson, ncarras@bu.edu

Published: 30 January 2009

This article is online at http://arthritis-research.com/content/11/1/203

(c) 2009 BioMed Central Ltd

Arthritis Research \& Therapy 2009, 11:203 (doi:10.1186/ar2531)

\begin{abstract}
With the recognition that osteoarthritis is a disease of the whole joint, attention has focused increasingly on features in the joint environment which cause ongoing joint damage and are likely sources of pain. This article reviews current ways of assessing osteoarthritis progression and what factors potentiate it, structural abnormalities that probably produce pain, new understandings of the genetics of osteoarthritis, and evaluations of new and old treatments.
\end{abstract}

Osteoarthritis (OA) is the most common form of arthritis and remains one of the few chronic diseases of aging for which there is little, if any, effective treatment. It accounts for more mobility disability in the elderly than any other disease. Symptomatic knee OA affects roughly $12 \%$ of persons 60 years old or older and, despite medical advances, remains for many a major source of pain and function limitation. Hip $\mathrm{OA}$, though less prevalent than disease in the knee, is common and frequently disabling, and hand OA causes pain and function loss in a large percentage of the elderly. Given the aging of the population and the increasing occurrence of obesity in our population, a major risk factor for disease, estimates suggest a doubling in prevalence from 2000 to 2020 [1].

We will focus on developments in our clinical understanding of $\mathrm{OA}$ in the last 10 years. This period has seen major changes in our conceptualization of the disease, the widespread introduction of magnetic resonance imaging (MRI) in clinical studies (a tool that has permitted us to better visualize structural changes within $\mathrm{OA}$ joints), and the emergence of large-scale clinical studies investigating mechanical and loading abnormalities as risk factors for disease. The results of these studies have led to changes in our approach to treatment. The discussion will target knee OA, which has been the best studied of all joints affected. Advances in the medical understanding of hip and hand OA will also be reviewed.

\section{New conceptualizations of osteoarthritis} While the signature pathologic feature of $O A$ is hyaline articular cartilage loss, it is increasingly recognized that $\mathrm{OA}$ is a disease of the whole joint and that all structures are affected [2]. Not only is hyaline cartilage lost, but bone remodeling and attrition occur relatively early in the disease process [3]. Fibrocartilage degeneration including the meniscus and labrum (in the hip) is integral to disease, and changes in the load-distributing function of this fibrocartilage may induce injury to adjacent hyaline cartilage. Chondroosteophytes, protrusions of new cartilage which subsequently ossify, form both at the joint margin and centrally at areas where cartilage has eroded. The synovium often develops lining cell hyperplasia and in some cases becomes infiltrated with subsynovial inflammatory cells [4]. Activated synovium secretes excess synovial fluid, leading to capsular swelling. This swelling, through a spinal reflex, inhibits complete activation of muscles bridging the joint (arthrogenous inhibition) and this, combined with lack of use, leads to muscle weakness and atrophy. The inflammation present in the synovium triggers changes in the peripheral nervous system, affecting the afferent processing of nociceptive signals from the joint and surrounding tissues. Thus, OA pathologically affects all structures of the joint and understanding the process of disease and its progression necessitates an appreciation for how changes in one of these structures (for example, the meniscus) may affect others.

A major driver of the development of disease and its progression is aberrant loading, or mechanopathology (both microscopic and macroscopic). When the joint is young and healthy, complex and overlapping systems protect it from injury. These include the muscles across the joint which contract in a smooth coordinated fashion through the excursion of the joint, coordination informed by nervous system inputs. Also included are the frictionless lubrication of surfaces during movement and competent ligaments that

ADAPT = Arthritis, Diet, and Activity Promotion Trial; AM = adduction moment; BML = bone marrow lesion; COX-2 = cyclooxygenase-2; IL-1 = interleukin-1; MOST = Multicenter Osteoarthritis Study; MRI = magnetic resonance imaging; NSAID = non-steroidal anti-inflammatory drug; OA = osteoarthritis; WOMAC $=$ Western Ontario and McMaster Universities Osteoarthritis Index. 
provide limits to joint excursion. Normal anatomy means that the distances between the bones produce loading that is distributed physiologically across the joint during movement. When cartilage erosion occurs or a knee ligament becomes injured and fails to limit physiologic motion, loading becomes unevenly distributed. This localized excess loading leads to further damage and malalignment within the joint during movement. Either malalignment or local stepoffs within the joint subject the cartilage (both fibro and hyaline) to excess focal loading, producing progressive damage. The joint becomes grossly malaligned during movement, and at the site of malalignment, focal loading is excessive, accelerating damage. Muscles may no longer work in a smooth coordinated fashion, and inflammation within the joint may cause further nervous system and muscle changes. This picture of mechanopathology contributing to pathology in multiple joint tissues that interact with one another to accelerate that pathology represents the picture of fully developed disease. Hyaline articular cartilage loss, a defining feature of disease, is only a small part of this picture.

A new insight into the pathology of $O A$ has been the recognition that modest enthesitis is a common feature. In early hand $\mathrm{OA}$, there is inflammation at the boney insertion of the collateral ligaments [5] and histological examination shows synovitis investing the ligament insertion sites [6]. In knees, similar bone lesions are seen on MRI near the insertion sites of intact anterior and posterior cruciate ligaments in $\mathrm{OA}$ knees [7].

The focus on cartilage loss may have served as a distraction from the main clinical feature of OA: pain. Cartilage is aneural, and longitudinal studies have suggested that cartilage loss and pain relief are poorly, if at all, correlated $[8,9]$. Investigations of the nature of pain in OA and of the relation of pain with specific structural features have provided new insights into how OA may be successfully managed.

\section{The symptoms of osteoarthritis: pain and instability}

The pain of $\mathrm{OA}$ is activity-related, with pain coming on generally only when a person does specific activities that induce it. For example, in persons with knee OA, walking up and down stairs often produces pain whereas lying in bed frequently does not. However, recent work suggests that this simple description of activity pain in $\mathrm{OA}$ is inadequate. In a qualitative study in which large numbers of persons with knee and hip OA were interviewed, Hawker and colleagues [10] identified two different types of pain experienced by patients. The first was a chronic and constant dull aching that for most patients was expected and did not affect their lifestyle or inhibit their activities. The second was a much more stressful and anxiety-provoking flare of pain that in end-stage disease often occurred unexpectedly and without an obvious trigger. Early in disease, pain was only episodic and its precipitants were known and pain episodes were self-limited. By the time one got severe disease, pain became chronic and superimposed on that chronic pain were unanticipated episodes of severe pain.

There are other elements to the pain in OA which may have implications for treatment. First [11], depressive symptoms are far more common in patients with painful OA than previously recognized, and sleep disorders may occur in these patients which may magnify their pain. Furthermore, many of these patients use descriptors for pain (for example, burning) which suggest that their pain has neuropathic elements.

Functional pain occurs when a person alters behavior to avoid pain that injures a part of the body (for example, removing a finger from a burning stove). All pain in OA is probably not functional. Synovitis-induced inflammatory changes within the joint may, in turn, have effects on peripheral nervous system inputs at the spinal cord level, inducing both peripheral and ultimately central changes in pain processing. Kosek and Ordeberg [12] were intrigued by the often widespread pain experienced by patients with hip OA, suggesting that more than just the receptor area for the hip is involved in nociception. They tested patients with hip OA for the presence of central nervous system sensitization. Sensitization is tested by evaluating whether another noxious stimulus inhibits the pain produced by a painful stimulus like hip OA. These investigators tested 15 patients with unilateral painful hip OA versus age- and gender-matched controls and found that noxious stimulation (in this case, a blood pressure cuff overinflated to produce ischemia) did not reduce pain sensitivity in the non-OA leg in patients, whereas it did so normally in controls. This provides strong evidence of central sensitization in patients with hip OA. Intriguingly, after these patients underwent hip replacement surgery, they were retested and their noxious inhibitory control had returned to normal. These findings of dysfunctional pain in patients with OA leave room for treatment that focuses solely on pain relief, including potent analgesics and molecules that block nervous system transmission of pain. Pain can also serve as a protective mechanism for a person to avoid activities that lead to more joint damage. Thus, there is a theoretical risk to pure analgesic treatment which will need to be studied.

As noted by Hawker and colleagues [10], constant pain becomes a feature of $\mathrm{OA}$ later in the disease. If pain does not abate (even if it is relatively mild), a person is more likely to need a knee or hip replacement than if pain is severe but intermittent. Consistent pain tends to occur when structural disease is advanced and when the patient has co-existing depressive symptoms that are more depressive [13].

Pain is not the only symptom of OA experienced by patients with knee and hip OA. They also frequently experience a sensation of instability or buckling. The most common symptom is one of shifting or instability without actually falling or giving way. However, giving way or buckling is also 
common and leads to a high rate of falls in persons with knee OA. Of adults in middle and elderly years from the Framingham study [14], 12\% experienced one episode of knee buckling in the previous 3 months and, in many of these, buckling led to falls. Most persons with buckling had both knee pain and more than one episode of buckling. Persons with knee buckling were more functionally disabled than those without it, even adjusting for the severity of their knee pain. Buckling in the knee may reflect weakness of muscles such as the quadriceps, which stabilize the joint during activities like stair climbing. Strengthening exercises and balance training may be therapeutic [15]. If buckling occurs with activities involving switching direction when walking, a tear of the anterior cruciate ligament needs to be investigated, but most people who are middle-aged or older who have knee buckling have no such tear. Buckling also tends to be more common in persons who have pain in multiple joints in their legs, not just the knee.

\section{The relation of pain to structural pathology in osteoarthritis}

Since cartilage is aneural, other structures within the joint must be the source of pain in OA. Historical and anatomical studies suggested that pain fibers can be identified in the synovium, in ligaments especially near their insertions, in bone, in muscle, and in the outer third of the meniscus in the knee. In an unusual study in which the lead investigator became the study subject and underwent an awake unanesthetized arthroscopy, Dye and colleagues [16] probed different knee structures and found that, whereas articular cartilage was not tender, ligament insertion sites and the synovium were.

A series of studies has focused on features that appear abnormal on knee MRI in those with and without pain. The majority of the studies have been conducted among persons who have radiographic knee $\mathrm{OA}$ and have compared those with and without knee pain with the idea that MRI can identify pathology in pain-sensitive structures such as the synovium, the meniscus, the bone, and capsular distension with fluid.

Patients with knee OA often have poorly circumscribed lesions in the bone marrow on MRI. Painful knees are more likely to demonstrate these lesions than non-painful knees. For example, Felson and colleagues [17] showed that, of persons with x-ray OA and chronic pain, 37\% had large bone marrow lesions (BMLs) in their knees on MRI versus only $2 \%$ of OA knees that were not painful (for comparison of BMLs in painful versus non-painful knees, $P<0.001)$. The relation of large BMLs with pain was confirmed by Sowers and colleagues [18] but not by Kornaat and colleagues [19]. To the extent that we can assess cartilage loss, studies suggest that BMLs [20] are strongly related to risk of loss, especially overlying the lesion.

BMLs are not the only bone feature related to pain in OA. Attrition of bone is more common in persons with knee pain

\section{Figure 1}

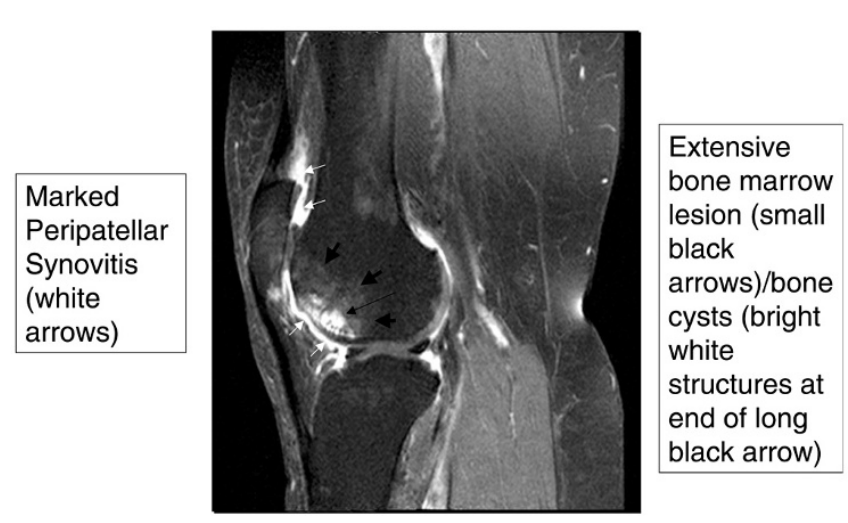

Gadolinium-enhanced magnetic resonance image (sagittal view) of a knee with multiple structural features typical of osteoarthritis. There are bone marrow lesions, cysts, and synovial thickening.

and OA than OA persons without knee pain [21]. The truth is that, by the time a knee has severe pain and shows evidence of $\mathrm{OA}$ on $\mathrm{MRI}$, many pathologic features coexist, making it difficult to identify the single feature that causes pain (Figure 1). Because of the coexistence of these lesions, investigators increasingly have looked at whether change in specific MRI features over time correlates with change in pain. In a report from the Multicenter Osteoarthritis Study (MOST) looking at compartment-specific BMLs in knees of persons with no knee pain at baseline followed for 15 months with repeated MRIs, Felson and colleagues [22] reported that new-onset knee pain was related to an increase in size of BMLs on MRI. Of 110 cases with new-onset knee pain, 49.1\% demonstrated an increase in compartmental BML scores compared with $26.8 \%$ of controls $(n=220$, $P<0.001)$. Most people with increasing size of BMLs had BMLs at baseline. Of those with no BMLs at baseline, new BMLs occurred in $32.4 \%$ of cases compared with $10.8 \%$ of controls.

Other features linked to pain in knee OA are synovitis and effusions. Using non-contrast-enhanced MRI, which yields an incomplete view of synovitis, Hill and colleagues [23] reported that change in synovitis on MRI was positively correlated with change in severity of knee pain in 270 persons with symptomatic knee OA who had undergone serial MRls. The correlation, though significant, was only modest ( $r=0.21, P=0.0003)$, translating into an increase in pain visual-analogue scale score (on a 0 to 100 scale) of 3.15 [23] per one-grade increase in synovitis ( 0 to 9 scale). This longitudinal study suggested that a diminution in synovitis would reduce pain. The findings of $\mathrm{Hill}$ and colleagues have been corroborated by Zhang and colleagues [24], who used data from serial MRls in the MOST study and found that change in synovitis score was strongly related to change in pain - a decrease in score being associated with a 
lower pain score. The presence of a knee effusion and its size are also correlated with the occurrence of pain in the knee, and change in effusion size relates directly (bigger effusion, more pain) to change in pain [22].

Lastly, patients sometimes have knee pain that originates outside the joint. Hill and colleagues [25] demonstrated that periarticular MRI findings (including semimembranosus-tibial collateral ligament bursitis, anserine bursitis, iliotibial band syndrome, or tibiofibular cyst) were more common in those with knee pain (15\%) than in those without it $(4 \%$, $P=0.004)$. The frequency of peripatellar lesions was not significantly different between participants with and without pain (12\% versus $21 \%$, respectively).

\section{Structural progression of osteoarthritis}

Even as MRI has become increasingly used to study disease, methods of $x$-ray imaging have been refined so that $x$-ray acquisition is now standardized with scoring and measurements that permit accurate and reproducible characterization of disease progression. Joint space loss in the medial compartment can be assessed as a proxy for medial cartilage loss. Some methods require fluoroscopic positioning, which is hard to standardize across centers [26]. Other methods using fixed knee flexion are easier to standardize. One of these uses a positioning frame that permits a highly reproducible assessment of the joint space [27]; this method is widely used in longitudinal studies. While joint space loss has been recommended as a way to track knee OA progression [28], there are inherent problems with measuring joint space loss on $x$-ray over time. First, this measurement focuses on the medial joint but approximately $20 \%$ of patients with knee OA sustain lateral compartment progression that leads to pseudowidening of the medial joint. Second, much of the joint space is filled by the meniscus, especially at its periphery, and meniscal extrusion frequently can lead to joint space loss [29]. Lastly, even tiny differences in the beam angle of the $x$-ray from baseline to follow-up lead to substantial differences in joint space width, producing spurious estimates of loss or gain. Different strategies have been adopted to overcome these problems with the $x$-ray. One is the addition of lateral weight-bearing views [30]. On the lateral view, the tibiofemoral joint can provide complementary information on the tibiofemoral joint to that imaged by the posteroanterior or anteroposterior view. In addition, semiquantitative scoring can provide information on lateral, medial, and patellofemoral joint progression, and experienced $x$-ray readers are sometimes more accurate in characterizing joint space loss than ruler-based measurements, especially when tiny beam angle changes that they can discount have occurred. In persons at high risk of progression, such as older persons who are obese, progression rates on the radiograph can reach $50 \%$ or more over the course of 30 months [31]. In the hip, joint space loss much more accurately represents cartilage loss than in the knee. The hip is rounder, making it easier to acquire images straight through the joint.
Plus, there is no intervening soft tissue like the meniscus that confounds the measurement of cartilage thickness.

In many studies, the MRI image has supplanted knee $x$-rays as a way of evaluating cartilage loss. Amin and colleagues [32] showed that knee x-rays have a sensitivity of only about $25 \%$ for cartilage loss seen on MRI. The $x$-ray underestimates cartilage loss occurring in the posterior sweep of the femur and often in the upslope of the medial and lateral compartments near the cruciate ligaments. Unfortunately, although early estimates suggested that cartilage loss would occur at a rate of about $5 \%$ per year [33] among OA knees, recent large-scale work from the OA Initiative suggests that, among OA knees, the rate of cartilage loss is far less than this, only about $2 \%$ per year [34]. Such a low rate of loss coupled with variability of measurement makes studies evaluating factors that might affect cartilage loss highly challenging and also makes drug development work difficult. Current efforts focus on identifying a subgroup at high risk of loss in which new treatments might be tested. Further measurement work in cartilage loss may be necessary before it can be optimized. There may be subregions where loss in rapid and can be measured reproducibly. Semiquantitative scoring of cartilage continues to play an important role because focal erosions are present early in disease and are not well detected by quantitative measurements that summarize cartilage across a larger region [3]. Semiquantitative scoring also incorporates scores for knee joint features outside cartilage such as the meniscus and bone marrow.

\section{Risk factors for disease progression: understanding why the structure of the joint deteriorates}

With the advent of standardized radiographs and the introduction of MRI into clinical research in OA, several new natural history studies of persons with $\mathrm{OA}$ have been carried out, looking at factors that affect the likelihood of structural progression that in $\mathrm{x}$-ray studies is defined as joint space loss and in MRI studies as cartilage loss. These studies cannot be summarized easily since they use different techniques for examining structural progression and test different risk factors. X-ray studies generally do not evaluate MRI-assessed risk factors such as meniscal tears or extrusion. MRI studies are complicated by their tendency to evaluate risk factors for cartilage loss at each of multiple anatomic sites.

In studies using MRI examining mechanical risk factors, there are three risk factors that are consistently and strongly related to cartilage loss: malalignment of the tibiofemoral joint, BMLs, and meniscal disease manifested either as a tear or as extrusion. Sharma and colleagues [35] reported that malalignment based on mechanical axis measurement was strongly related to joint space loss on x-ray, and subsequent studies $[20,36]$ have reported that malalignment strongly predicts the likelihood of cartilage loss on MRI too. If the knee 
is varus, cartilage loss will be medial, and if valgus, lateral compartment loss will occur.

BMLs markedly increase the risk of later cartilage loss, especially loss in a region of the joint superficial to the lesion [20]. These lesions are strongly related to malalignment [37], with medial BMLs occurring when the knee is varus and lateral lesions when the knee is valgus. Adjusting for malalignment attenuates the relationship of BMLs with progression, suggesting that malalignment explains much of the relation of BMLs with disease progression. Interestingly, Pelletier and colleagues [38] followed 107 patients with knee $\mathrm{OA}$, a smaller number than in the other studies, and reported that medial compartment cartilage volume loss was correlated with lateral BMLs more significantly than it was with medial lesions, a finding that requires further investigation.

The last factor consistently related to cartilage loss or joint space loss is meniscal disease manifested either as tears or as meniscal extrusion. The latter phenomenon occurs when enough substance of the meniscus has been torn, especially at the meniscal root posterior to the knee, that the meniscus is no longer tethered to its attachments and can float freely outside the knee. When such extrusion occurs, it narrows the joint on x-ray [39] and also increases the risk of cartilage loss [36] since extrusion is functionally equivalent to having no meniscus at all, a major known risk factor for cartilage loss. Meniscal tears, because they may alter the load-distributing function of the meniscus, even when there is no extrusion, also increase the risk of cartilage loss $[36,38]$. Just as tibiofemoral malalignment predisposes to cartilage loss in the tibiofemoral compartments of the knee, so patellar malalignment, either medial or lateral, predisposes to cartilage loss in the respective patellar compartment [40].

The risk factors for new-onset $\mathrm{OA}$ may differ from those associated with increased risk of progression in those who already have disease. The presence of hand OA, probably a proxy for generalized $\mathrm{OA}$, appears to increase the risk that a person will get new-onset knee and hip OA [41]. Hand OA has also been noted to increase the risk of knee OA in those with meniscal tears who are at high risk of developing knee OA [42].

The focus of most progression studies had been on cartilage loss, and too little attention has been paid to change in pain or function in persons with knee OA. Roos and colleagues [43] reported a 7-year follow-up of persons undergoing meniscectomy, many of whom had OA at baseline. Older age at time of operation and higher body mass index were factors that accelerated the loss in function. Interestingly, a high body mass index has been tied in multiple studies to worse pain and function but not necessarily to greater structural progression.

The course of OA varies from person to person. Some with knee OA experience little change in pain or function and little structural progression. Others note a rapid downhill course.
Changes in pain and function appear to have little relation to the trajectory of structural progression. What produces this variety in disease trajectory is not clear. Identifying sources of heterogeneity might permit the identification of factors that keep disease stable and therefore could be tested as treatments. Those with malalignment at the knee experience both rapid structural progression and functional deterioration [35]. In fact, malalignment is such a potent risk factor for tibiofemoral progression that, especially among those with severe varus malalignment, other risk factors such as obesity appear to have little effect on the disease course [44]. Thus, some of the heterogeneity of the disease path is likely to be due to the presence or absence of malalignment across the joint.

\section{Genetics of osteoarthritis}

The proportion of OA due to genetic contributions varies by joint. Upwards of $50 \%$ of the occurrence of hip and hand OA may be due, in part, to genetic inheritance, whereas the percentage of knee OA varies in different population studies from non-detectably low values to up to $40 \%$. In the general population, little knee $\mathrm{OA}$ is heritable, but among middleaged women with bilateral disease occurring at an early age, heritability reaches $40 \%$.

Large-scale studies using the genome-wide association approach are under way worldwide, and individual cohort studies are reporting that particular genes or polymorphisms within genetic regions predispose to high rates of OA. In general, many reported genetic associations reported by one group are not replicated by other cohorts and turn out to be chance findings. However, in $\mathrm{OA}$, some associations have been replicated, suggesting that there really are genes that confer high rates of disease in these chromosomal regions. The most consistently confirmed genetic association is for a gene coding secreted frizzled-related protein-3 (usually called FRZB), an association reported especially in relation to the risk of hip OA in women [45]. The function of this gene is to serve as an antagonist to Wnt signaling proteins that play roles in the development of cartilage during growth and control chondrocyte maturation [46]. A mutation associated with $\mathrm{OA}$ does not inhibit Wnt signaling as well as the wildtype, resulting in more beta-catenin translocation to the nucleus and activation of transcription factors that increase metalloproteinase production or cartilage destruction.

Interleukin-1 (IL-1) has a multitude of functions in cartilage and in synovium within the joint. In most activities, the net effect of IL-1 is to promote cartilage degradation. Genomewide scans have suggested that a gene conferring increased risk of OA lies within the IL-1 cluster on chromosome $2 q$. While confirmed in several different cohorts, the specific gene conferring risk could be IL-1, an antagonist to IL-1, a different interleukin, or even another gene close by [47].

Other genes have been reported as related to OA risk but independent replication of these associations has not been 
clear-cut. Undoubtedly, as meta-analyses are performed combining cohorts and providing more power to detect associations, other genes will be uncovered that increase OA risk. This will provide new understandings of how OA can develop and what treatments might be designed.

\section{Non-surgical treatments of osteoarthritis}

While recent studies have tested new treatments for OA, many have failed to identify treatments that successfully modify the structural pathology of OA or prevent joint deterioration. Successful approaches have included those targeting pain and inflammation and others focused on rehabilitation strategies. Those will be reviewed here.

\section{Non-steroidal inflammatory drugs and cyclooxygenase-2 inhibitors}

For many years, on the basis of small older trials, it was felt that anti-inflammatory drugs and analgesics such as paracetamol were equipotent for OA treatment. A series of large multi-center trials has disproved this notion, showing unequivocally that both anti-inflammatory drugs and cyclooxygenase-2 (COX-2) inhibitors are more efficacious for the treatment of pain and functional limitation than paracetamol is. In a meta-analysis of five OA trials, Wegman and colleagues [48] showed a standardized mean difference favoring non-steroidal anti-inflammatory drugs (NSAIDs) over paracetamol for pain of 0.33 (95\% confidence interval 0.15 to 0.51 ), indicating a small effect. Pincus and colleagues [49] reported not only that celecoxib was more effective than acetaminophen but that $53 \%$ of patients preferred celecoxib and only $24 \%$ preferred acetaminophen, with the remainder not expressing a preference. Even low-dose ibuprofen (400 mg/day) was found to be significantly more efficacious than high-dose acetaminophen in one large-scale trial [50]. In a large crossover trial Pincus and colleagues [49] showed that, once patients had received NSAIDs, their chances of responding to acetaminophen, when switched to it later, were extremely low. That informed current guidelines for OA treatment, which advise that acetaminophen be used only early in treatment of $O A$ and report that once patients have been tried on NSAIDs they are very unlikely to experience benefits should they be switched back to acetaminophen.

While anti-inflammatory therapies are more efficacious than acetaminophen for OA, their relative efficacy is not much greater and this creates difficult treatment decisions because of the high toxicity rates of many NSAIDs and COX-2 inhibitors. In fact, because of the increased rates of cardiovascular events associated with COX-2 inhibitors and with some conventional NSAIDs [51], many of these drugs are not appropriate long-term treatment choices for older persons with OA, especially those at high risk of heart disease or stroke. The American Heart Association and a meta-analysis of trials [52] have identified rofecoxib and all other COX-2 inhibitors as putting patients at high risk [51], although low doses of celecoxib, such as $200 \mathrm{mg} /$ day, may not be associated with risk. One widely used NSAID, diclofenac, has predominant COX-2-inhibiting actions and its use is associated with elevated risks of cardiovascular disease, making it similar in risk to COX-2 inhibitors. Diclofenac should be avoided for most long-term uses in OA. The only safe drug from the perspective of cardiovascular risk is naproxen, and the risk is not elevated compared with nonusers or with acetaminophen users. For some NSAIDs such as nabumetone and non-acetylated salicylates, there are insufficient data to characterize cardiovascular risk. This includes such drugs as ibuprofen, whose use may or may not be associated with an increase in risk. lbuprofen may interact with low-dose aspirin, negating the cardioprotective effects of the latter, especially if the two drugs are taken at the same time.

NSAIDs also cause an increased risk of gastrointestinal toxicity, and the switch from COX-2 inhibitor use back to conventional NSAIDs may be accompanied by a temporal increase in gastrointestinal events attributable to NSAID use without use of gastroprotective drugs. Strategies to avoid the high risk of NSAID-related gastrointestinal side effects (Table 1) include the use of low doses of NSAID or use on an as-needed basis. Other tactics include the selection of NSAIDs with a lower risk of gastrointestinal side effects, the concurrent use of gastroprotective drugs, and the selection of patients who are at low risk, including those who have no coexistent Helicobacter pylori infection, and other high-risk patients. A composite of meta-analyses of large observational studies [53-56], which have evaluated the comparative gastrointestinal side effects of NSAIDs, is shown in Table 2, in which drugs are ranked according to their gastrointestinal risk. For many patients with OA, choosing a safe NSAID and keeping the dose low can help to avoid side effects. For those at higher gastrointestinal risk, adding a proton pump inhibitor, misoprostol, or a double dose of $\mathrm{H} 2$ blocker [57] can minimize gastrointestinal risk.

\section{Topical non-steroidal anti-inflammatory drugs}

With the 2007 approval by the US Food and Drug Administration of topical diclofenac and the availability of these agents in Europe, clinicians have a choice of administration modality for anti-inflammatory drugs. NSAIDs are placed into a gel or topical solution with another chemical moiety that enhances penetration of the skin barrier. When NSAIDs are absorbed through the skin, plasma concentrations are an order of magnitude lower than with the same amount of drug administered orally or parenterally. However, when these drugs are administered topically in proximity to a joint (for example, on top of the knee), the drug can be found in joint tissues such as the synovium and cartilage [58].

Clinical trials of topical NSAIDs versus placebo have not all been positive, and there is a troubling tendency for all published trials to be industry-funded. There may be publication bias of topical NSAID trials, the failure of small trials that show no effect to be published [59]. This 
Table 1

\section{Strategies to decrease the gastrointestinal risk of non- steroidal anti-inflammatory drugs}

1. Use non-steroidal anti-inflammatory drugs (NSAIDs) at low dose and intermittently

2. Avoid use if untreated Helicobacter pylori present

3. Avoid combined use with corticosteroids or aspirin

4. Use with proton pump inhibitors (alternatives include a double dose of $\mathrm{H} 2$ blockers or misoprostol)

5. Choose benign NSAID/cyclooxygenase-2

6. Avoid use in persons with prior gastrointestinal (Gl) bleeding ulcers, upper Gl surgery

Table 2

Gastrointestinal risk of non-steroidal anti-inflammatory drugs/cyclooxygenase-2 from safest to riskiest

\begin{tabular}{|c|c|}
\hline Safer & Nonacetylated salicylates (for example, salsalate) \\
\hline & Nabumetone \\
\hline & Celecoxib \\
\hline & Ibuprofen \\
\hline 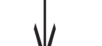 & Diclofenac \\
\hline & Sulindac \\
\hline & Naproxen \\
\hline & Indomethacin \\
\hline Riskier & Ketoprofen \\
\hline
\end{tabular}

The table summarizes evidence from a series of studies [53-56].

publication bias suggests that readers may not have access to all evidence collected on topical NSAIDs, and should be skeptical of published trial information. Compared with placebo in three published trials, topical diclofenac led to a 1.6-unit improvement in WOMAC (Western Ontario and McMaster Universities Osteoarthritis Index) pain score (which has a range of 0 to 20) [60]. Results of trials comparing the efficacies of topical with oral NSAIDs have generally found that topical NSAIDs are slightly less efficacious than oral agents $[61,62]$. In a large trial based on general practices in England, for patients given topical versus oral ibuprofen, pain improvement in the oral ibuprofen group was superior, especially at 12 and 24 months after starting treatment, and discontinuation for inadequate pain relief occurred in $23 \%$ of patients on topical drug versus only $13 \%$ in those on oral drug [63]. The major advantage of topical therapy is that it has fewer gastrointestinal side effects and renal and blood pressure-related side effects $[59,60,62]$ than oral NSAIDs. Unfortunately, topical NSAIDs often cause local skin irritation where the medication is applied, inducing redness, burning, or itching in up to $40 \%$ of patients (Table 3 ).

\section{Rehabilitative approaches to osteoarthritis treatment}

\section{a. Bracing or taping}

Taping or bracing a joint can immobilize it. This can relieve pain in a joint that is painful when used or can realign a joint that has become malaligned. Taping or bracing may also improve impaired neurosensory input around the joint and, by doing so, improve motor function. Treatments with taping or bracing have been tested in knee OA, especially for patients with disease affecting either the patellofemoral or medial tibiofemoral compartments.

One of the most efficacious treatments has been patellar taping, which shows impressive effects on pain relief in patients with patellar pain and patellofemoral $\mathrm{OA}$ and perhaps even those with knee pain in general $[64,65]$. The exact mechanism by which adhesive tape placed over the superior aspect of the patella works to relieve pain is not clear. There is conflicting evidence as to whether it actually alters patellar malalignment. Even so, trials have strongly suggested that this treatment relieves pain [64-66]. The limitations may be that it is not easy to educate patients on how to apply tape themselves and that the adhesive tape that one applies may irritate the skin. As a consequence of limitations of taping, brace studies for the patella are currently ongoing. The effects of patellar braces on patellar malalignment are also unclear, but braces may push the patella into the trochlear groove [67], thereby increasing the contact area of the patella and decreasing focal stress.

Tibiofemoral bracing has also been shown to be efficacious [68]. In a randomized trial of patients with medial disease, Kirkley and colleagues [68] tested a brace versus neoprene sleeve versus no treatment at all and found that the neoprene sleeve relieved pain better than nothing but that the brace relieved pain better than either of the other two treatments as measured by the WOMAC, a survey that asks persons about knee pain during five different activities and produces a score reflecting pain severity. In those with varus OA, tibiofemoral braces straighten the knee slightly [69], decreasing varus malalignment. Braces are an underused treatment for medial $\mathrm{OA}$, in part because adherence with them in the long term is not high, especially among older persons with disease.

\section{b. Orthotics/shoes}

Adduction moment (AM) is the largest moment arm across the knee during gait and represents the dynamic equivalent of static varus alignment. Persons with painful medial knee OA often adapt their gaits in ways that are presumed to lessen pain because the adaptations lower AM. For example, when off analgesics, persons with medial knee OA walk with their toes out, decreasing the AM, but when on effective analgesics and in little pain, they walk with toes in, allowing their AMs to increase [70]. AM has been shown in those without knee pain to predict those at high risk of getting it [71]. AM is the most powerful risk factor yet described for 
Table 3

\begin{tabular}{lll}
\hline \multicolumn{2}{l}{$\begin{array}{l}\text { Comparison of oral and topical non-steroidal anti- } \\
\text { inflammatory drugs for osteoarthritis }\end{array}$} & \\
\hline & Oral & Topical \\
\hline Efficacy & More potent & Less potent \\
Tolerability & Moderate-Poor & Moderate-Good \\
$\begin{array}{l}\text { Common side } \\
\text { effects }\end{array}$ & $\begin{array}{l}\text { Upper gastrointestinal } \\
\text { symptoms and bleed, } \\
\text { ulcer; worsening renal } \\
\text { function }\end{array}$ & Skin irritation \\
& & \\
\hline
\end{tabular}

medial joint progression [72]. Lowering AM has become a major goal of biomechanical treatments of medial knee OA.

Certain shoes and insoles have been designed so that, when worn or inserted, they lower knee AM. However, in trials, use of these shoes and insoles has not translated consistently to improved pain in knee OA patients [73-75]. The reasons may include insufficient decrease in AM (only $6 \%$ on average) with great variability in AM change from patient to patient [76], failure of short-term effects to translate to longer term gait effects, and failure to identify patients who would be most likely to benefit (for example, some have patellofemoral pain). Shoes and insoles remain a promising treatment for medial knee OA, but one in which the ultimate goal of pain relief has not been realized.

\section{c. Exercise}

Multiple trials testing different types of exercise regimens are consistent in showing that exercise alleviates pain from knee OA. Even aquatic exercise appears to be modestly effective and may be better tolerated than land-based exercise. However, there are a number of substantial concerns about exercise as a treatment option for patients. First, the effect is (on average) only modest, with a number of patients not experiencing any pain benefit (and some even getting worse). Second, adherence to exercise over the long term in this chronic illness is poor. For example, in one large randomized trial [77], roughly $50 \%$ of people stopped exercising entirely by the 16-month follow-up, and in many trials adherence rates are worse than that.

How can adherence be improved? Hurley and colleagues [78], who achieved a high rate of adherence at 6 months $(82 \%)$, suggested that elements explaining this success included individualizing treatment, instilling confidence that exercise would not be harmful, reassuring patients that initial positive effects were likely to continue, and teaching coping strategies. Rejeski and colleagues [79], who carried out an 18-month exercise intervention, reported that the only people who had high adherence at the end were those who had high adherence to exercise soon after it was prescribed. Campbell and colleagues [80] conducted an interview study and found that patients would exercise over the long term only if they felt that exercise improved their OA symptoms. Since all types of exercise appear to be effective, it may be best to prescribe the type of exercise most acceptable to the patient as this may be one most likely to encourage adherence.

Exercise is also a necessary component of a weight loss intervention for obese patients with knee OA. Unfortunately, the only large-scale intervention examining weight loss and exercise, the Arthritis, Diet, and Activity Promotion Trial (ADAPT) [77], suggested that, for knee OA patients, weight loss itself had only a modest and non-significant effect on pain and function. Exercise by itself did not significantly improve symptoms (the modest effect of exercise on pain in this trial was similar to its effect in other trials [81]). The combination of exercise and weight loss treatment in the ADAPT trial had an especially large effect that reached significance compared with an attention control group. Results of this study emphasize the modest effect of exercise, the necessity of coupling weight loss with exercise, and the impressive effect of combined treatment. For hip OA, individual studies have not consistently reported that exercise is efficacious. However, a recent meta-analysis pulling together data from all of the individual hip OA trials has strongly supported the notion that exercise is efficacious versus attention control [82]. Unfortunately, as in knee OA, exercise for hip OA has only modest efficacy.

\section{Conclusion}

Over the last 10 years, major advances in our understanding of clinical OA have occurred in areas as diverse and fundamental as a change in conceptualization of disease, our understanding of factors that affect its progression, our appreciation for the breadth and complexity of symptoms, and our approach to treatment. Among changes has been our recognition of the central role of clinical mechanopathology, including malalignment and factors in the local joint environment such as muscle and meniscal pathology in the knee. Also, we have a new appreciation for structural abnormalities in the joint such as BMLs and synovitis that

\section{The Scientific Basis
of Rheumatology:}

This article is part of a special collection of reviews, The Scientific Basis of Rheumatology: A Decade of Progress, published to mark Arthritis Research \& Therapy's 10th anniversary.

Other articles in this series can be found at: http://arthritis-research.com/sbr 
probably cause pain. Lastly, new approaches to treatment, including topical NSAIDs, knee bracing and patellar taping along with exercise regimens, have offered new options to our patients with disease.

\section{Competing interests}

The author declares that he has no competing interests.

\section{Acknowledgments}

I am indebted to Frank Roemer for help with MRI images. This review was supported by NIH AR47785.

\section{References}

1. Felson DT, Zhang Y: An update on the epidemiology of knee and hip osteoarthritis with a view to prevention. Arthritis Rheum 1998, 41:1343-1355.

2. Brandt KD, Doherty M, Lohmander LS: Introduction: the concept of osteoarthritis as failure of the diarthrodial joint. In Osteoarthritis. Edited by Brandt K, Doherty M, Lohmander LS. Oxford, UK: Oxford University Press; 2003:69-71.

3. Reichenbach S, Guermazi A, Niu J, Neogi T, Hunter DJ, Roemer FW, McLennan CE, Hernandez-Molina G, Felson DT: Prevalence of bone attrition on knee radiographs and MRI in a community-based cohort. Osteoarthritis Cartilage 2008, 16:1005-1010.

4. Aigner TV: Osteoarthritis and inflammation - inflammatory changes in osteoarthritic synoviopathy. In Osteoarthritis, Inflammation and Degradation: A Continuum. Edited by Buckwater J. Amsterdam: IOS Press; 2007:219-235.

5. Tan AL, Toumi H, Benjamin M, Grainger AJ, Tanner SF, Emery P, McGonagle D: Combined high-resolution magnetic resonance imaging and histological examination to explore the role of ligaments and tendons in the phenotypic expression of early hand osteoarthritis. Ann Rheum Dis 2006, 65:1267-1272.

6. Benjamin M, McGonagle D: Histopathologic changes at "synovio-entheseal complexes" suggesting a novel mechanism for synovitis in osteoarthritis and spondylarthritis. Arthritis Rheum 2007, 56:3601-3609.

7. Hernández-Molina G, Guermazi A, Niu J, Gale D, Goggins J, Amin S, Felson DT: Central bone marrow lesions in symptomatic knee osteoarthritis and their relationship to anterior cruciate ligament tears and cartilage loss. Arthritis Rheum 2008, 58: 130-136.

8. Torres L, Dunlop DD, Peterfy C, Guermazi A, Prasad P, Hayes KW, Song J, Cahue S, Chang A, Marshall M, Sharma L: The relationship between specific tissue lesions and pain severity in persons with knee osteoarthritis. Osteoarthritis Cartilage 2006, 14:1033-1040.

9. Amin S, Niu JB, Lavalley M, Guermazi A, Grigorian M, Hunter DJ, et al.: Cartilage loss of the knee on MRI is not related to progression of knee pain or disability [abstract]. Arthritis Rheum 2004, 50:S141-S142.

10. Hawker GA, Stewart L, French MR, Cibere J, Jordan JM, March L, Suarez-Almazor M, Gooberman-Hill R: Understanding the pain experience in hip and knee osteoarthritis-an OARSI/ OMERACT initiative. Osteoarthritis Cartilage 2008, 16:415-422.

11. Sale JE, Gignac M, Hawker G: The relationship between disease symptoms, life events, coping and treatment, and depression among older adults with osteoarthritis. J Rheumatol 2008, 35:335-342.

12. Ordeberg G: Characterization of joint pain in human OA. Novartis Found Symp 2004, 260:105-115.

13. Neogi T, Nevitt M, Zhu Y, Xie H, Curtis JR, Clark EC, et al.: Inconsistent knee pain: prevalence, predictors, and association with function [abstract]. Osteoarthritis Cartilage 2006, 14 (Suppl 2): S120-S121.

14. Felson DT, Niu J, McClennan C, Sack B, Aliabadi P, Hunter DJ, Guermazi A, Englund M: Knee buckling: prevalence, risk factors, and associated limitations in function. Ann Intern Med 2007, 147:534-540.

15. Fitzgerald GK, Piva SR, Irrgang JJ: Reports of joint instability in knee osteoarthritis: its prevalence and relationship to physical function. Arthritis Rheum 2004, 51:941-946.
16. Dye SF, Vaupel GL, Dye CC: Conscious neurosensory mapping of the internal structures of the human knee without intraarticular anesthesia. Am J Sports Med 1998, 26:773-777.

17. Felson DT, Chaisson CE, Hill CL, Totterman SM, Gale ME, Skinner KM, Kazis L, Gale DR: The association of bone marrow lesions with pain in knee osteoarthritis. Ann Intern Med 2001, 134:541-549.

18. Sowers MF, Hayes C, Jamadar D, Capul D, Lachance L, Jannausch $M$, Welch $G$ : Magnetic resonance-detected subchondral bone marrow and cartilage defect characteristics associated with pain and X-ray-defined knee osteoarthritis. Osteoarthritis Cartilage 2003, 11:387-393.

19. Kornaat PR, Bloem JL, Ceulemans RY, Riyazi N, Rosendaal FR, Nelissen RG, Carter WO, Hellio Le Graverand MP, Kloppenburg M: Osteoarthritis of the knee: association between clinical features and MR imaging findings. Radiology 2006, 239:811817.

20. Hunter DJ, Zhang Y, Niu J, Goggins J, Amin S, LaValley MP, Guermazi $A$, Genant $H$, Gale D, Felson DT: Increase in bone marrow lesions associated with cartilage loss: a longitudinal magnetic resonance imaging study of knee osteoarthritis. Arthritis Rheum 2006, 54:1529-1535.

21. Hernández-Molina G, Neogi T, Hunter DJ, Niu J, Guermazi A, Roemer FW, McLennan CE, Reichenbach S, Felson DT: The association of bone attrition with knee pain and other MRI features of osteoarthritis. Ann Rheum Dis 2007, May 14. [Epub ahead of print].

22. Felson DT, Niu J, Guermazi A, Roemer F, Aliabadi P, Clancy M, Torner J, Lewis CE, Nevitt MC: Correlation of the development of knee pain with enlarging bone marrow lesions on magnetic resonance imaging. Arthritis Rheum 2007, 56:2986-2992.

23. Hill CL, Hunter DJ, Niu J, Clancy M, Guermazi A, Genant H, Gale D, Grainger A, Conaghan P, Felson DT: Synovitis detected on magnetic resonance imaging and its relation to pain and cartilage loss in knee osteoarthritis. Ann Rheum Dis 2007, 66: 1599-1603.

24. Zhang Y, Lewis C, Torner J, Guermazi A, Roemer F, McCulloch C, et al.: Reversible MRI features and knee pain fluctuation: the MOST study [abstract]. Osteoarthritis Cartilage 2007, 15(suppl): C17.

25. Hill CL, Gale DR, Chaisson CE, Skinner K, Kazis L, Gale ME, Felson DT: Periarticular lesions detected on magnetic resonance imaging: prevalence in knees with and without symptoms. Arthritis Rheum 2003, 48:2836-2844.

26. Mazzuca SA, Brandt KD: Plain radiography as an outcome measure in clinical trials involving patients with knee osteoarthritis. Rheum Dis Clin North Am 1999, 25:467-480, ix.

27. Nevitt MC, Peterfy C, Guermazi A, Felson DT, Duryea J, Woodworth T, Chen H, Kwoh K, Harris TB: Longitudinal performance evaluation and validation of fixed-flexion radiography of the knee for detection of joint space loss. Arthritis Rheum 2007, 56:1512-1520.

28. Gossec L, Jordan JM, Mazzuca SA, Lam MA, Suarez-Almazor ME, Renner JB, Lopez-Olivo MA, Hawker G, Dougados M, Maillefert JF; OARSI-OMERACT task force "total articular replacement as outcome measure in OA": Comparative evaluation of three semi-quantitative radiographic grading techniques for knee osteoarthritis in terms of validity and reproducibility in 1759 X-rays: report of the OARSI-OMERACT task force. Osteoarthritis Cartilage 2008, 16:742-748.

29. Hunter DJ, Zhang YQ, Tu X, Lavalley M, Niu JB, Amin S, Guermazi A, Genant H, Gale D, Felson DT: Change in joint space width: hyaline articular cartilage loss or alteration in meniscus? Arthritis Rheum 2006, 54:2488-2495.

30. Lavalley MP, McLaughlin S, Goggins J, Gale D, Nevitt MC, Felson DT: The lateral view radiograph for assessment of the tibiofemoral joint space in knee osteoarthritis: its reliability, sensitivity to change, and longitudinal validity. Arthritis Rheum 2005, 52:3542-3547.

31. Felson D, Nevitt MC, Yang M, Clancy M, Niu J, Torner JC, Lewis CE, Aliabadi P, Sack B, McCulloch C, Zhang Y: A new approach yields high rates of $\mathrm{x}$-ray progression in knee osteoarthritis. $J$ Rheumatol 2008, 35:2047-2054.

32. Amin S, Lavalley MP, Guermazi A, Grigoryan M, Hunter DJ, Clancy M, Niu J, Gale DR, Felson DT: The relationship between cartilage loss on magnetic resonance imaging and radiographic progression in men and women with knee osteoarthritis. 
Arthritis Rheum 2005, 52:3152-3159.

33. Eckstein F, Cicuttini F, Raynauld JP, Waterton JC, Peterfy C: Magnetic resonance imaging (MRI) of articular cartilage in knee osteoarthritis (OA): morphological assessment. Osteoarthritis Cartilage 2006, 14 Suppl A:A46-A75.

34. Hunter DJ, Li J, Lavalley M, Bauer DC, Nevitt M, DeGroot J, Poole R, Eyre D, Guermazi A, Gale D, Felson DT: Cartilage markers and their association with cartilage loss on magnetic resonance imaging in knee osteoarthritis: the Boston Osteoarthritis Knee Study. Arthritis Res Ther 2007, 9:R108.

35. Sharma L, Song J, Felson DT, Cahue S, Shamiyeh E, Dunlop DD: The role of knee alignment in disease progression and functional decline in knee osteoarthritis. JAMA 2001, 286:188-195.

36. Sharma L, Eckstein F, Song J, Guermazi A, Prasad P, Kapoor D, Cahue S, Marshall M, Hudelmaier M, Dunlop D: Relationship of meniscal damage, meniscal extrusion, malalignment, and joint laxity to subsequent cartilage loss in osteoarthritic knees. Arthritis Rheum 2008, 58:1716-1726.

37. Felson DT, McLaughlin S, Goggins J, Lavalley MP, Gale ME, Totterman S, Li W, Hill C, Gale D: Bone marrow edema and its relation to progression of knee osteoarthritis. Ann Intern Med 2003, 139:330-336.

38. Pelletier JP, Raynauld JP, Berthiaume MJ, Abram F, Choquette D, Haraoui B, Beary JF, Cline GA, Meyer JM, Martel-Pelletier J: Risk factors associated with the loss of cartilage volume on weight-bearing areas in knee osteoarthritis patients assessed by quantitative magnetic resonance imaging: a longitudinal study. Arthritis Res Ther 2007, 9:R74.

39. Gale DR, Chaisson CE, Totterman SM, Schwartz RK, Gale ME, Felson D: Meniscal subluxation: association with osteoarthritis and joint space narrowing. Osteoarthritis Cartilage 1999, 7:526532 .

40. Hunter DJ, Zhang YQ, Niu JB, Felson DT, Kwoh K, Newman A, Kritchevsky S, Harris T, Carbone L, Nevitt M: Patella malalignment, pain and patellofemoral progression: the Health $A B C$ Study. Osteoarthritis Cartilage 2007, 15:1120-1127.

41. Dahaghin S, Bierma-Zeinstra SM, Reijman M, Pols HA, Hazes JM, Koes BW: Does hand osteoarthritis predict future hip or knee osteoarthritis? Arthritis Rheum 2005, 52:3520-3527.

42. Englund M, Paradowski PT, Lohmander LS: Association of radiographic hand osteoarthritis with radiographic knee osteoarthritis after meniscectomy. Arthritis Rheum 2004, 50: 469-475.

43. Roos EM, Bremander AB, Englund M, Lohmander LS: Change in self-reported outcomes and objective physical function over 7 years in middle-aged subjects with or at high risk of knee osteoarthritis. Ann Rheum Dis 2008, 67:505-510.

44. Felson DT, Goggins J, Niu J, Zhang Y, Hunter DJ: The effect of body weight on progression of knee osteoarthritis is dependent on alignment. Arthritis Rheum 2004, 50:3904-3909.

45. Loughlin J: The genetic epidemiology of human primary osteoarthritis: current status. Expert Rev Mol Med 2005, 7:112.

46. Loughlin J, Dowling B, Chapman K, Marcelline L, Mustafa Z, Southam L, Ferreira A, Ciesielski C, Carson DA, Corr M: Functional variants within the secreted frizzled-related protein 3 gene are associated with hip osteoarthritis in females. Proc Natl Acad Sci U S A 2004, 101:9757-9762.

47. Loughlin J, Dowling B, Mustafa Z, Chapman K: Association of the interleukin-1 gene cluster on chromosome $2 q 13$ with knee osteoarthritis. Arthritis Rheum 2002, 46:1519-1527.

48. Wegman A, van der Windt D, van Tulder M, Stalman W, de Vries T: Nonsteroidal antiinflammatory drugs or acetaminophen for osteoarthritis of the hip or knee? A systematic review of evidence and guidelines. J Rheumatol 2004, 31:344-354.

49. Pincus T, Koch G, Lei H, Mangal B, Sokka T, Moskowitz R, Wolfe F, Gibofsky A, Simon L, Zlotnick S, Fort JG: Patient Preference for Placebo, Acetaminophen (paracetamol) or Celecoxib Efficacy Studies (PACES): two randomised, double blind, placebo controlled, crossover clinical trials in patients with knee or hip osteoarthritis. Ann Rheum Dis 2004, 63:931-939.

50. Boureau F, Schneid H, Zeghari N, Wall R, Bourgeois P: The IPSO study: ibuprofen, paracetamol study in osteoarthritis. A randomised comparative clinical study comparing the efficacy and safety of ibuprofen and paracetamol analgesic treatment of osteoarthritis of the knee or hip. Ann Rheum Dis 2004, 63: 1028-1034
51. Antman EM, Bennett JS, Daugherty A, Furberg C, Roberts $H$, Taubert KA: Use of nonsteroidal antiinflammatory drugs: an update for clinicians: a scientific statement from the American Heart Association. Circulation 2007, 115:1634-1642.

52. Kearney PM, Baigent C, Godwin J, Halls H, Emberson JR, Patrono C: Do selective cyclo-oxygenase-2 inhibitors and traditional non-steroidal anti-inflammatory drugs increase the risk of atherothrombosis? Meta-analysis of randomised trials. BMJ 2006, 332:1302-1308.

53. Fries JF, Williams CA, Bloch DA: The relative toxicity of nonsteroidal antiinflammatory drugs. Arthritis Rheum 1991, 34: 1353-1360.

54. Lanza FL: Endoscopic studies of gastric and duodenal injury after the use of ibuprofen, aspirin, and other nonsteroidal anti-inflammatory agents. Am J Med 1984, 77:19-24.

55. Hernandez-Diaz S, Rodriguez LA: Association between nonsteroidal anti-inflammatory drugs and upper gastrointestinal tract bleeding/perforation: an overview of epidemiologic studies published in the 1990s. Arch Intern Med 2000, 160: 2093-2099.

56. Rostom A, Muir K, Dubé C, Jolicoeur E, Boucher M, Joyce J, Tugwell P, Wells GW: Gastrointestinal safety of cyclooxygenase-2 inhibitors: a Cochrane Collaboration systematic review. Clin Gastroenterol Hepatol 2007, 5:818-828.

57. Rostom A, Dube C, Wells G, Tugwell $P$, Welch V, Jolicoeur $E$ McGowan J: Prevention of NSAID-induced gastroduodenal ulcers. Cochrane Database Syst Rev 2002, (4):CD002296.

58. Mason L, Moore RA, Edwards JE, Derry S, McQuay HJ: Topical NSAIDs for chronic musculoskeletal pain: systematic review and meta-analysis. BMC Musculoskelet Disord 2004, 5:28

59. Lin J, Zhang W, Jones A, Doherty M: Efficacy of topical nonsteroidal anti-inflammatory drugs in the treatment of osteoarthritis: meta-analysis of randomised controlled trials. BMJ 2004, 329:324.

60. Towheed TE: Pennsaid therapy for osteoarthritis of the knee: a systematic review and metaanalysis of randomized controlled trials. J Rheumato/ 2006, 33:567-573.

61. Tugwell PS, Wells GA, Shainhouse JZ: Equivalence study of a topical diclofenac solution (pennsaid) compared with oral diclofenac in symptomatic treatment of osteoarthritis of the knee: a randomized controlled trial. J Rheumatol 2004, 31: 2002-2012.

62. Underwood M, Ashby D, Cross P, Hennessy E, Letley L, Martin J, Mt-Isa S, Parsons S, Vickers M, Whyte K; TOIB study team: Advice to use topical or oral ibuprofen for chronic knee pain in older people: randomised controlled trial and patient preference study. BMJ 2008, 336:138-142.

63. Underwood M, Ashby D, Cross P, Hennessy E, Letley L, Martin J, et al.: Advice to use topical or oral ibuprofen for clinical knee pain in older people; randomized controlled trial and patient preference stucy. BMJ 2008, 336:138-142.

64. Hinman RS, Crossley KM, McConnell J, Bennell KL: Efficacy of knee tape in the management of osteoarthritis of the knee: blinded randomised controlled trial. BMJ 2003, 327:135.

65. Warden SJ, Hinman RS, Watson MA Jr., Avin KG, Bialocerkowski $\mathrm{AE}$, Crossley KM: Patellar taping and bracing for the treatment of chronic knee pain: a systematic review and meta-analysis. Arthritis Rheum 2008, 59:73-83.

66. Cushnaghan J, McCarthy C, Dieppe P: Taping the patella medially: a new treatment for osteoarthritis of the knee joint? $B M J$ 1994, 308:753-755

67. Powers CM, Ward SR, Chen YJ, Chan LD, Terk MR: The effect of bracing on patellofemoral joint stress during free and fast walking. Am J Sports Med 2004, 32:224-231.

68. Kirkley A, Webster-Bogaert S, Litchfield R, Amendola A, MacDonald $S$, McCalden R, Fowler P: The effect of bracing on varus gonarthrosis. J Bone Joint Surg Am 1999, 81:539-548.

69. Pollo FE, Otis JC, Backus SI, Warren RF, Wickiewicz TL: Reduction of medial compartment loads with valgus bracing of the osteoarthritic knee. Am J Sports Med 2002, 30:414-421.

70. Hurwitz DE, Ryals AR, Block JA, Sharma L, Schnitzer TJ, Andriacchi TP: Knee pain and joint loading in subjects with osteoarthritis of the knee. J Orthop Res 2000, 18:572-579.

71. Amin S, Lavalley MP, Simms RW, Felson DT: The role of vitamin $D$ in corticosteroid-induced osteoporosis: a meta-analytic approach. Arthritis Rheum 1999, 42:1740-1751.

72. Miyazaki T, Wada M, Kawahara H, Sato M, Baba H, Shimada S: 
Dynamic load at baseline can predict radiographic disease progression in medial compartment knee osteoarthritis. Ann Rheum Dis 2002, 61:617-622.

73. Pham T, Maillefert JF, Hudry C, Kieffert P, Bourgeois P, Lechevalier $D$, Dougados $M$ : Laterally elevated wedged insoles in the treatment of medial knee osteoarthritis. A two-year prospective randomized controlled study. Osteoarthritis Cartilage 2004, 12:46-55.

74. Baker K, Goggins J, Xie H, Szumowski K, Lavalley M, Hunter DJ, Felson DT: A randomized crossover trial of a wedged insole for treatment of knee osteoarthritis. Arthritis Rheum 2007, 56: 1198-1203.

75. Erhart JC, Giori NJ, Andriacchi TP: Variable-stiffness walking shoe lowers knee adduction moment, reduces pain, and improves function in patients with osteoarthritis after one year. Paper presented at: 54th Annual Meeting of the Orthopaedic Research Society; 2-5 March 2008; San Francisco, CA, USA.

76. Hinman RS, Bowles KA, Payne C, Bennell KL: Effect of length on laterally-wedged insoles in knee osteoarthritis. Arthritis Rheum 2008, 59:144-147.

77. Messier SP, Loeser RF, Miller GD, Morgan TM, Rejeski WJ, Sevick MA, Ettinger WH Jr., Pahor M, Williamson JD: Exercise and dietary weight loss in overweight and obese older adults with knee osteoarthritis: the Arthritis, Diet, and Activity Promotion Trial. Arthritis Rheum 2004, 50:1501-1510.

78. Hurley MV, Walsh NE, Mitchell HL, Pimm TJ, Patel A, Williamson $\mathrm{E}$, Jones RH, Dieppe PA, Reeves BC: Clinical effectiveness of a rehabilitation program integrating exercise, self-management, and active coping strategies for chronic knee pain: a cluster randomized trial. Arthritis Rheum 2007, 57:1211-1219.

79. Rejeski WJ, Brawley LR, Ettinger W, Morgan T, Thompson C: Compliance to exercise therapy in older participants with knee osteoarthritis: implications for treating disability. Med Sci Sports Exerc 1997, 29:977-985.

80. Campbell R, Evans M, Tucker M, Quilty B, Dieppe P, Donovan JL: Why don't patients do their exercises? Understanding noncompliance with physiotherapy in patients with osteoarthritis of the knee. J Epidemiol Community Health 2001, 55:132-138.

81. van Baar ME, Assendelft WJ, Dekker J, Oostendorp RA, Bijlsma JW: Effectiveness of exercise therapy in patients with osteoarthritis of the hip or knee: a systematic review of randomized clinical trials. Arthritis Rheum 1999, 42:1361-1369.

82. Hernández-Molina G, Reichenbach S, Zhang B, Lavalley $M$, Felson DT: Effect of therapeutic exercise for hip osteoarthritis pain: results of a meta-analysis. Arthritis Rheum 2008, 59: 1221-1228. 